\title{
Article
}

\section{A recent trend of drug-nanoparticles in suspension for the application in drug delivery}

Gurpreet, SS, Amritvir, K and Sen, Tapas

Available at http://clok.uclan.ac.uk/16398/

Gurpreet, SS, Amritvir, K and Sen, Tapas ORCID: 0000-0002-0463-7485 (2016) A recent trend of drug-nanoparticles in suspension for the application in drug delivery. Nanomedicine, 11 (21). pp. 2861-2876. ISSN 1743-5889

It is advisable to refer to the publisher's version if you intend to cite from the work. http://dx.doi.org/10.2217/nnm-2016-0238

For more information about UCLan's research in this area go to http://www.uclan.ac.uk/researchgroups/ and search for < name of research Group>.

For information about Research generally at UCLan please go to http://www.uclan.ac.uk/research/

All outputs in CLoK are protected by Intellectual Property Rights law, including Copyright law. Copyright, IPR and Moral Rights for the works on this site are retained by the individual authors and/or other copyright owners. Terms and conditions for use of this material are defined in the policies page.

\section{CLoK}

Central Lancashire online Knowledge www.clok.uclan.ac.uk

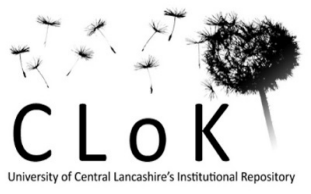




\section{Nanomedicine}

\section{A recent trend of drug-nanoparticles in suspension for the application in drug delivery}

\begin{tabular}{|r|l|}
\hline Journal: & Nanomedicine \\
\hline Manuscript ID & NNM-2016-0238.R1 \\
\hline Manuscript Type: & Review \\
\hline Keywords: & Targeting, Nanomaterials, Controlled drug release \\
\hline \multicolumn{2}{|l}{} \\
\hline
\end{tabular}

\section{SCHOLARONE}

Manuscripts 


\section{A recent trend of drug-nanoparticles in suspension for the application in drug} delivery

Gurpreet S. Suri ${ }^{1^{*}}$, Amritvir Kaur ${ }^{1}$, Tapas Sen $^{1^{*}}$

${ }^{*}$ corresponding authors details

${ }^{1}$ Nano-biomaterials Research Group (www.senlabs.org)

School of Physical Sciences \& Computing

Centre of Materials Sciences,

University of Central Lancashire,

Preston, PR1 2HE, United Kingdom

Tel: $\quad+441772894371$

Email: tsen@uclan.ac.uk or gurpreetbunny@gmail.com 
Nanomedicine

Page 2 of 29

ABSTRACT

Persistent development in nanomedicine has enabled successful nano-sizing of most drug samples, which in turn imparts remarkable properties to the drugs such as enhanced solubility and bioavailability for the applications in drug delivery. In this context, several review articles are available in scientific domain covering inorganic nanoparticles such as $\mathrm{Au}, \mathrm{Ag}$, SPIONs, Qdots, carbon nanotube and grapheme however this review covers the development of drug nanoparticles together with their possibilities and limitation from fabrication (bottom up vs top down) to application in drug delivery during the last 5 years. In addition, some distinguished studies and novel drug particles are presented in order to contribute significantly towards the understanding of drug nanocrystals and its use in drug delivery.

Keywords: Nano-suspension, Amorphous / Crystalline nanoparticles, Top down / Bottom up, Drug-nanocrystals, Nano-carriers, Drug Delivery

2

https://mc04.manuscriptcentral.com/fm-nnm 
Introduction

Modern material science is no longer restricted to the metallurgical application, as the advancement in the nanotechnology is opening unlocked doors in various fields. For over a decade, extensive research is being undertaken using nanoparticles for its application in medicines, environmental projects, electrical and electronics, aerospace and lifestyle industries. These nanoparticles of nanometer in size ranging from 1 to $1000 \mathrm{~nm}$ possess great advantages as compared to the microsized particles.

Development of a large number of drugs and their delivery without any side effects to the patients are the real challenges faced by scientific community. Most of the drug molecules are large organic molecules and have poor solubility in water. Hence a huge effort has been made for nanosizing the drug particles in either an amorphous or crystalline nanosuspension for applications in passive targeting due to enhanced membrane diffusion. Similarly an effort has been made for the development of several carriers for delivering drugs and functionalisation of carriers to enhance the active delivery at a target organ. Furthermore, the nanosize of drug particles imparts remarkable properties to the drugs such as enhanced solubility and bioavailability. Therefore this review is focussed on critically highlighting the nanomedical use of various drug nanocrystals, especially for drug delivery applications.

\section{Recent trends}

Nanoparticles' use has increased exponentially for the drug formulations and drug delivery in the last decade. Increased efforts are applied to monitor the structure function relationship of the nanoparticles for targeted drug delivery applications. There has been some novel nanodrugs produced recently such as the Copazone, Welchol, VivaGel and RenaGel. Copazone is a random co-polymer of the four main amino acids which is employed to treat muscular sclerosis ${ }^{[1]}$. Welchol is a drug which helps to lower the low density lipoprotein (LDL) cholesterol and blood sugar level by binding the cholesterol ${ }^{[2]}$. VivaGel is a topically administered vaginal virucide which is a multivalent lysine based dendrimer product ${ }^{[3]}$. RenaGel is an oral polymeric sequestrant that binds to phosphate and is used to treat chronic kidney disease ${ }^{[4]}$. In addition, a timeline is reviewed in Figure 1 to show the FDA approved amorphous and crystalline drugs since $1984^{[5]}$. 


\section{Timeline of FDA approvals}

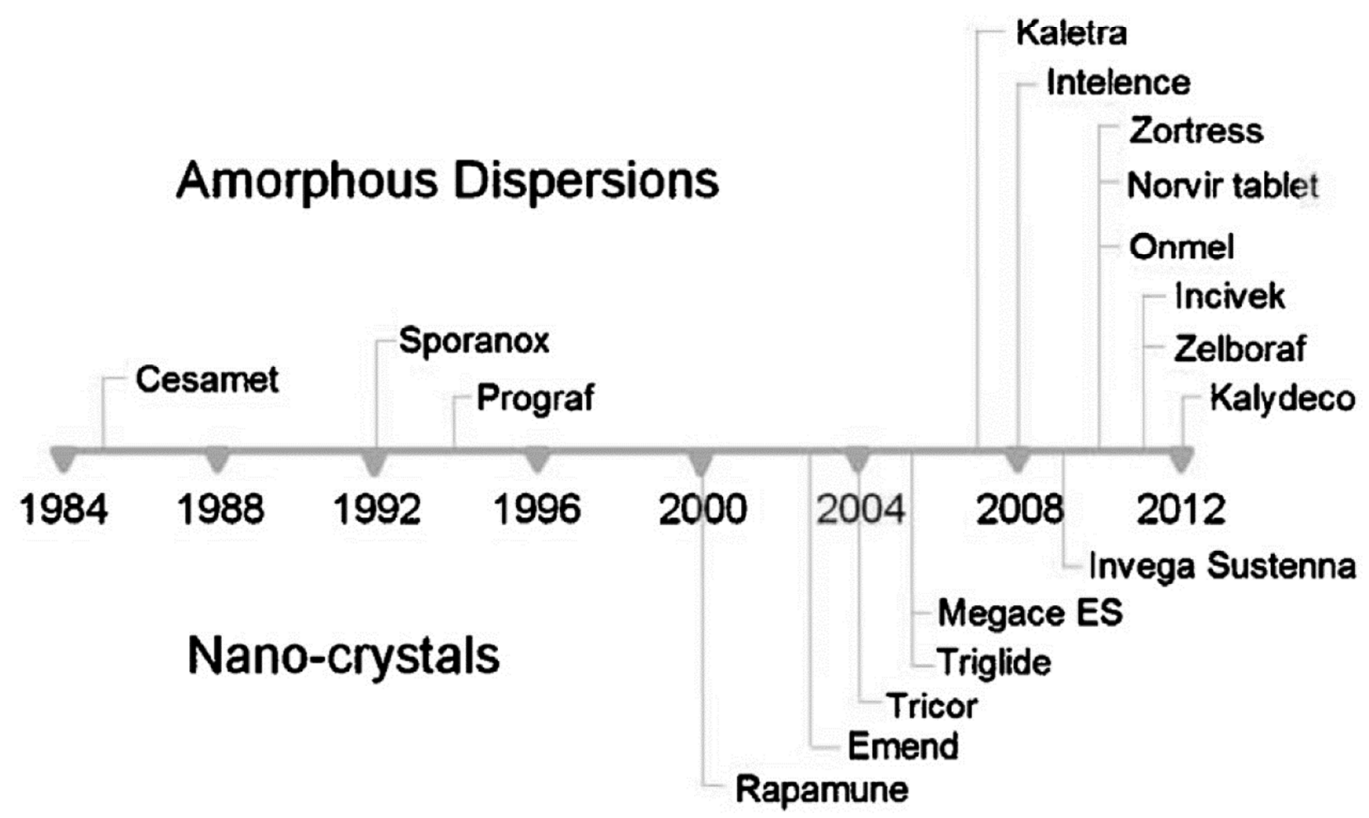

Figure 1: Timeline reviewing FDA approved crystalline \& amorphous drugs

(Reproduced with permission from ref [5])

Most of the current cancer therapies and drug formulations are based on the nanoparticle approach to improve the bioavailability and solubility of the encapsulated drugs at the target site. There is an increased use of nanosuspensions for drug delivery application, especially for topically administered drugs since nanosuspensions increases the bioavailability of drugs due to increased permeation. For instance, as shown in Figure 2, nanosuspensions exhibit higher permeability and high concentration gradient for both topical and subcutaneously administered drugs compared to microparticles ${ }^{[6]}$. A multi-disciplinary principle is employed nowadays to tailor the nanoparticles in order to incorporate specific properties, such as DNA functionalisation using molecular biology and genetics, ion conductivity using the semiconductor physics, solubility and stability using the organic chemistry, and so on. For example, $\beta$-Lapachone or simply $\beta$-Lap is a novel anticancer drug demonstrated to be delivered by $30 \mathrm{~nm}$ PEG-PLA polymer micelles to the lungs of mice. The drug was injected intravenously and was bioactivated by the enzyme $\mathrm{NAD}(\mathrm{P}) \mathrm{H}$ :quinon oxidoreductase-1 (NQO1) that is found in excess levels at the nonsmall-cell lung cancer sites ${ }^{[7]}$. 


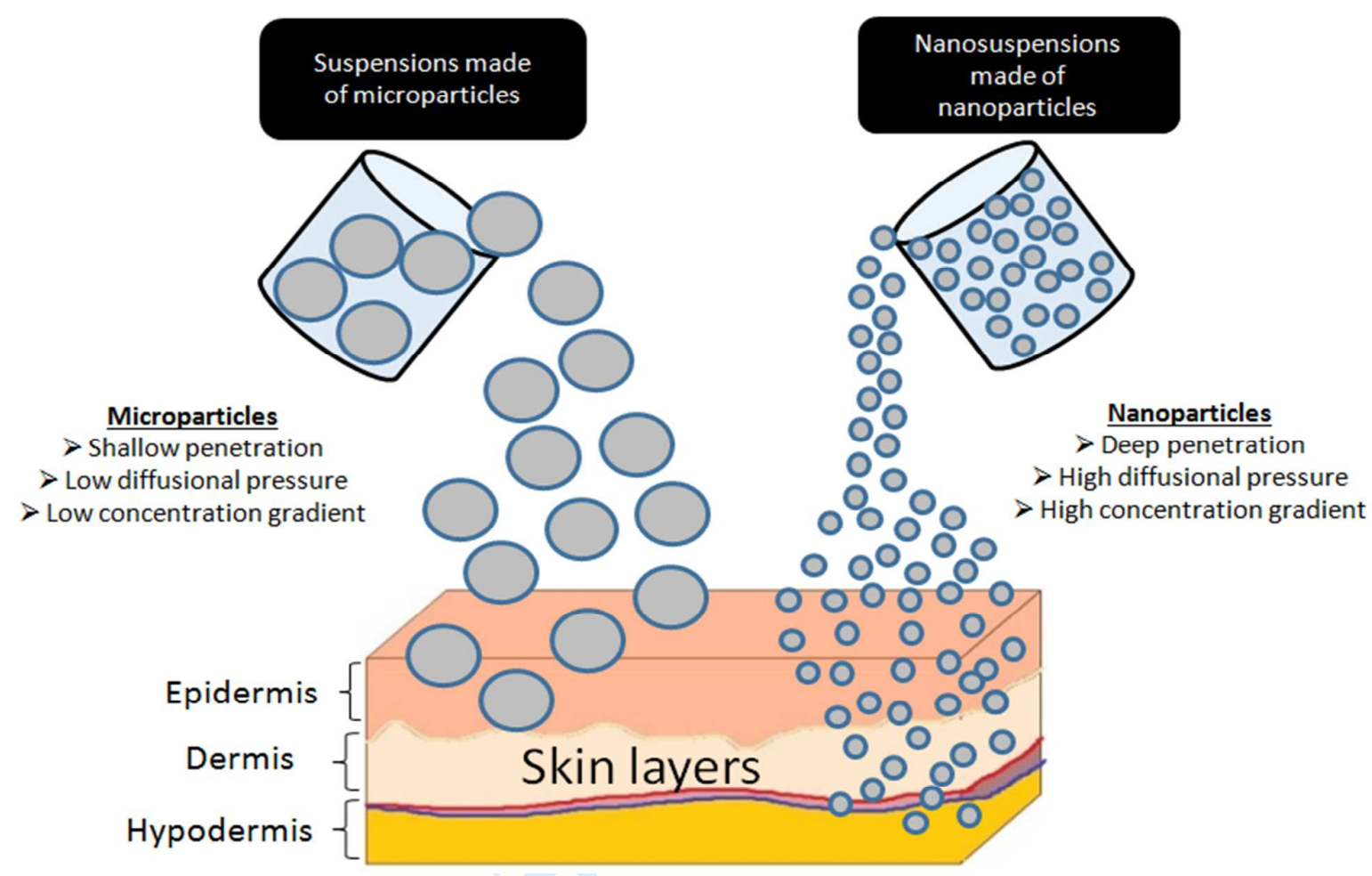

Figure 2: Scheme showing enhanced permeability of drug nanosuspension

\section{Drug particles in Nanosuspension}

In simple terms, a submicron colloidal dispersion of the nanoparticles (in either amorphous or crystalline form) is called as a nanosuspension. A drug specific nanosuspension consists of dispersed, finely colloidal and mostly biphasic drug particles with an overall size of less than $500 \mathrm{~nm}{ }^{[8]}$. These drug-nanoparticles conjugates can be stabilised using polymers and surfactants before administration through various routes such as topical, oral, pulmonary, ocular or parenteral [6]. Different ingredients are used for formulation of nanosuspensions such as organic solvents, cosurfactants, stabilisers and other additives such as salts, polyols, buffers, cryoprotectants and osmogents ${ }^{[9]}$.

Solubility and bioavailability of drugs are the key issues that are mitigated using the nanosuspensions. In addition, the nanosuspension also affects the drug's pharmacokinetics that can improve its efficacy and safety. Both chemical and physical modifications are applied to improve the solubility and bioavailability of drugs ${ }^{[10]}$. Chemical modifications include synthesising the soluble salts and prodrugs, whereas the physical modifications include reducing particle size, use of 
surfactants for solublisation/complexation, forming pseudo-polymorphs/polymorphs and preparing drug dispersions ${ }^{[11-15]}$. Different types of composite structure results from nanoparticles in suspension, as shown in Figure 3. Various factors and techniques are responsible to form composite structures such as the core shell, internal dispersion, agglomeration, coating/surface modification, hollow, porous, nano-dense body, nano-porous body and nano-thin film ${ }^{[16]}$.

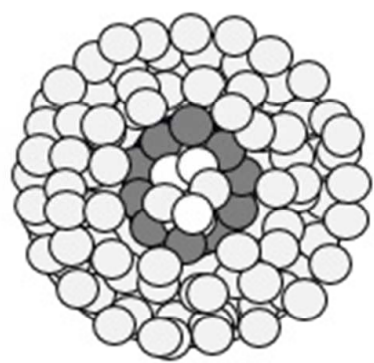

Core shell nanoparticles

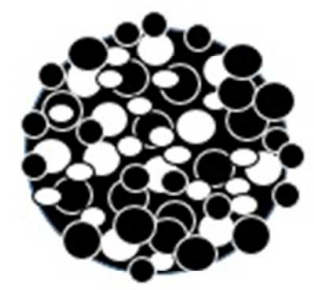

Internal dispersed nanoparticles

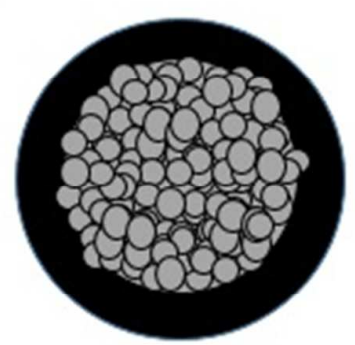

Magnetite shell nanoparticles

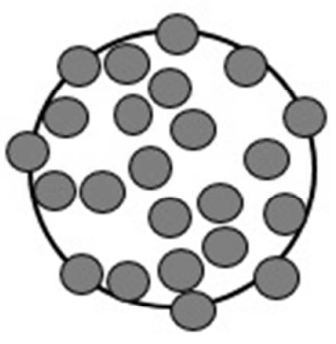

Coated nanoparticles

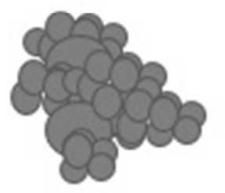

Agglomerated nanoparticles

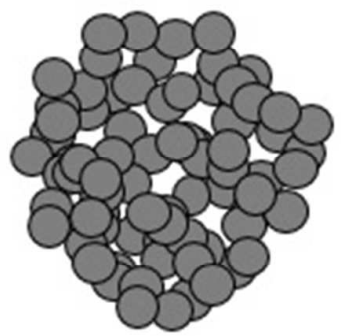

Porous nanoparticles

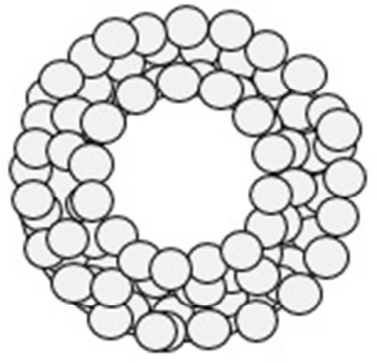

Hollow

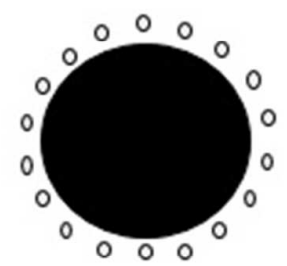

Surface functionalized nanoparticles

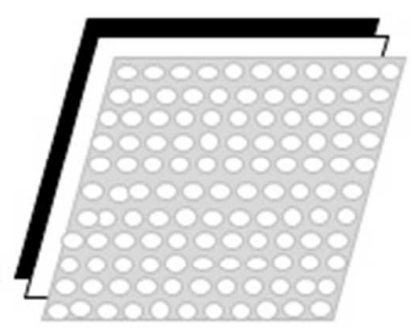

Thin layer Nano film

Figure 3: Types of composite structures formed from nanoparticles in suspension

\section{Functionalisation of nanocrystals}

A schematic review of the various ligands surface functionalised on a nanocrystals core is shown in Figure $4^{[17]}$. It can be seen that a drug nanocrystal core can be surface modified for specific applications by tailoring the type of ligands attached to it 
with the help of a polymer coating. For instance, magnetic ligands can be used for magnetically targeting to tumor sites followed by hyperthermia applications, where the drug could be released systematically due to localised hearing. The use of image contrast ligand facilitates the diagnostic monitoring of drug release and provide real time data about the pharmacokinetics of the drug. Furthermore, the surface of nanocrystal core could be functionalised with uptake, targeting or adhesion ligands to provide an active transport or targeting to tumor sites in in vivo. For instance, nanocrystal implants are exploiting these surface functionalised drug nanocrystals as therapeutic vehicles to identify, transfect and rebuild damaged regions in the body [18].

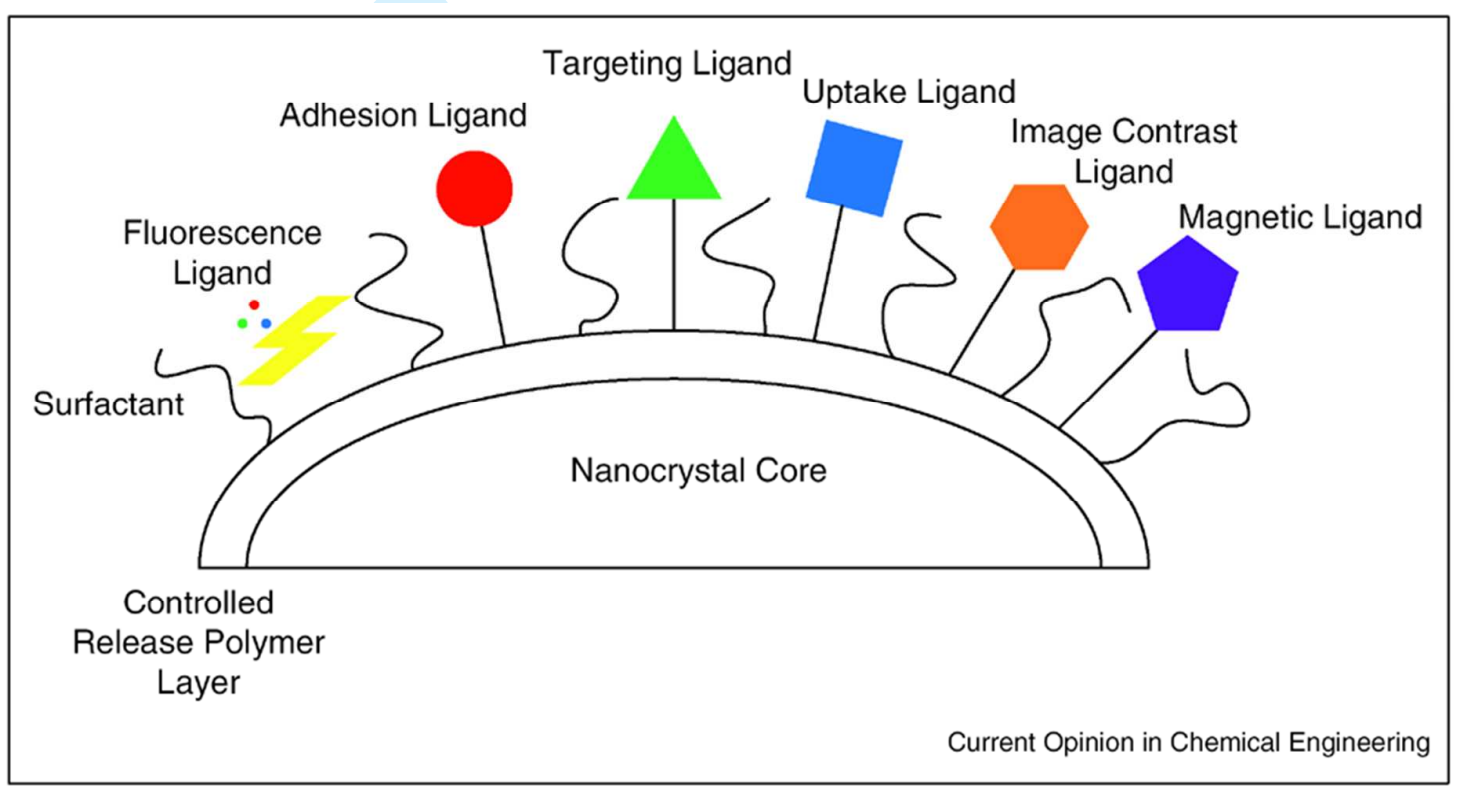

Figure 4: Surface functionalization of nanocrystals (Reproduced with permission from ref [17])

\section{Methods of preparation of nanosuspension}

Nanosuspensions can be prepared using both bottom-up and top-down approaches. These methodologies are widely applied in nanomedicine due to its consistency to produce nanoparticles of controlled aspect ratio ${ }^{[19]}$. The bottom-up methods are called as conventional precipitation methods whereas the top-down methods are referred to as disintegration methods. The top-down methods are further classified as media milling and high pressure homogenisation $(\mathrm{HPH})$ methods, where the latter 
is sub-classed into DissoCubes (HPH in water), Nanopure (HPH in nonaqueous media) and Nanoedge (HPH and precipitation) ${ }^{[20]}$. Figure 5 present a schematic diagram of two different approaches for the fabrication of drug nanoparticles.

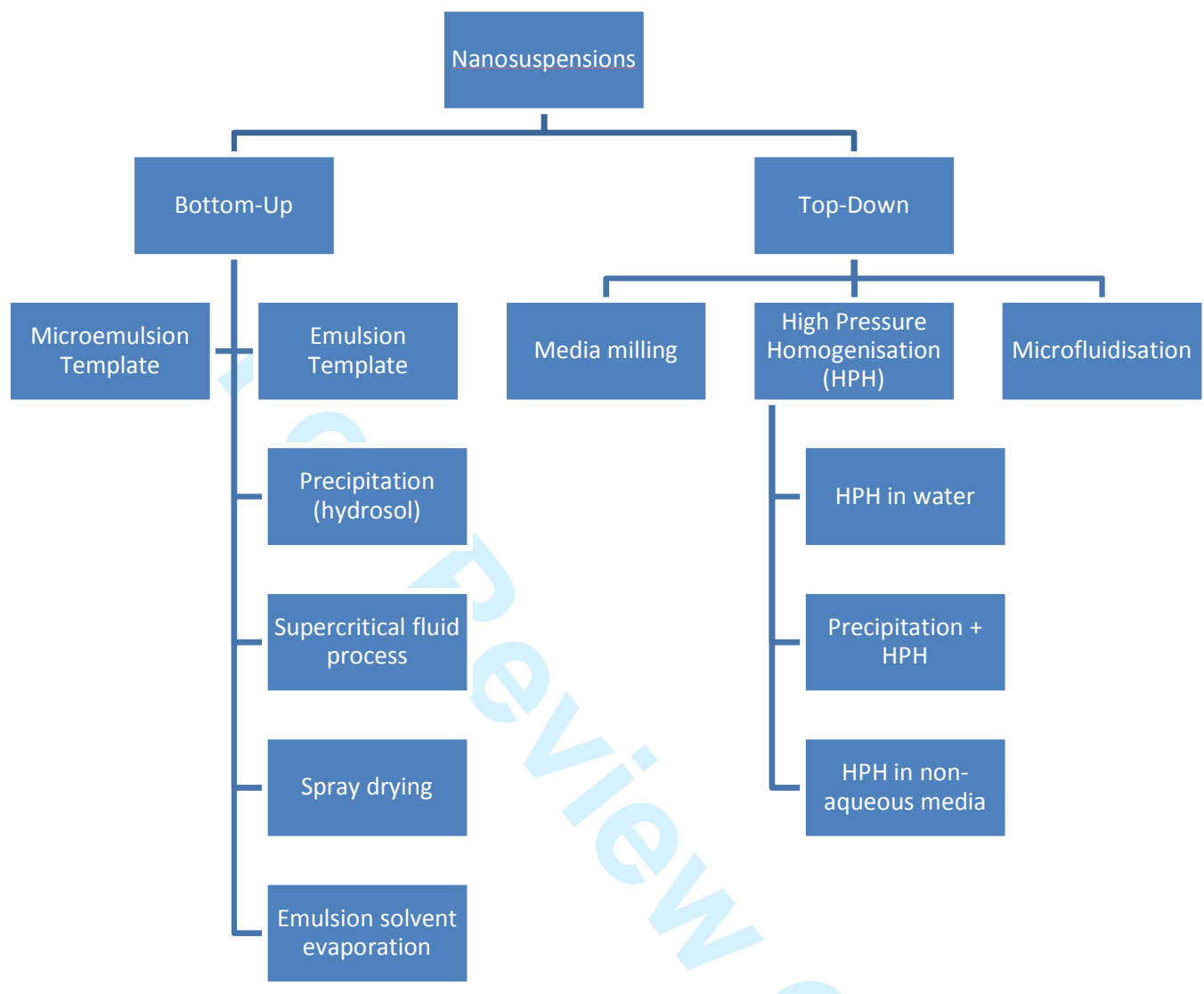

Figure 5: Various methods of nanosuspension preparation

Top down method of nanosuspension preparation aims to reduce particle size into nanoparticles using wet milling techniques such as high pressure homogenisation, microfluidisation and media milling. There are no harmful solvents used in these techniques but media milling method requires high energy inputs ${ }^{[21]}$. In general, considerable amounts of heat is generated in the top down methods leading to destruction of heat sensitive drug components. For example, milling is reported to cause mechanical activation at surfaces of drug particles ${ }^{[22]}$. High surface energetics lead to generation of amorphous regions and crystal defects. Further crystallisation of the drug particles reduces the physical and chemical stability of particles on storage $^{[23]}$. 
Bottom up method of nanosuspension preparation aims to produce nanoparticles from precipitate by first dissolving the drug in an organic solvent followed by adding a precipitating agent in the presence of a stabiliser ${ }^{[24]}$. Some forms of this method include supercritical fluid processes, solvent anti-solvent method, emulsion solvent evaporation and spray drying. Some of the limitations of bottom up method include generation of unstable polymorphs, solvates and hydrates of the nanosuspension constituents ${ }^{[25,26]}$. Furthermore, the difficulty of completing removing the solvents from the final product is persistent in bottom up method. This reduces the physical and chemical stability of the formulation, as it is often seen that bottom up method results in needle shaped particles due to rapid unidirectional growth ${ }^{[24]}$.

A study of some of the recent nanosuspensions prepared through various routes for drug delivery is shown in table $1^{[27-42]}$. The table highlights both amorphous and crystalline nanosuspensions along with the particle size, method of preparation and main conclusions from the studies. 
Table 1: A study of the recent (5 years) drug nanoparticles in both crystalline and amorphous forms [27 - 42$]$

\begin{tabular}{|c|c|c|c|c|c|c|}
\hline $\begin{array}{c}\text { Type of } \\
\text { nanoparticle }\end{array}$ & $\begin{array}{l}\text { Particle } \\
\text { size } \\
(\mathrm{nm})\end{array}$ & Drug/Polymer used & $\begin{array}{l}\text { Method of } \\
\text { preparation }\end{array}$ & Focus of article & Conclusion & Ref \\
\hline $\begin{array}{l}\text { Amorphous } \\
\text { nanoparticle } \\
\text { suspension }\end{array}$ & 350 & Cylosporin A (CyA) & Bead milling & $\begin{array}{c}\text { Enhance applications in } \\
\text { psoriasis or dermal } \\
\text { penetration }\end{array}$ & $\begin{array}{l}\text { Higher penetration using } \\
\text { amorphous CyA } \\
\text { nanoparticles }\end{array}$ & 27 \\
\hline $\begin{array}{l}\text { Amorphous } \\
\text { nanosuspension }\end{array}$ & $50-500$ & Isradipine & Sonoprecipitation & $\begin{array}{l}\text { Enhance drug delivery for } \\
\text { increased dissolution rates }\end{array}$ & $\begin{array}{l}\text { Improved drug release rate } \\
\text { was observed }\end{array}$ & 28 \\
\hline $\begin{array}{l}\text { Nanosuspension } \\
\text { (crystalline to } \\
\text { amorphous) }\end{array}$ & $300-500$ & Myricetin & $\begin{array}{l}\text { Nanosizing } \\
\text { process }\end{array}$ & $\begin{array}{l}\text { Effect of stabilizers on } \\
\text { bioavailability/ dissolution of } \\
\text { poorly water-soluble drugs }\end{array}$ & $\begin{array}{l}\text { Stabilizers enhanced } \\
\text { dissolution, amorphisation } \\
\text { enhanced solubility }\end{array}$ & 29 \\
\hline $\begin{array}{l}\text { Nanosuspension } \\
\text { (crystalline to } \\
\text { amorphous) }\end{array}$ & $208-246$ & $\begin{array}{l}\text { Cur-TPGS NSs } \\
\text { (Curcumin-D- } \alpha- \\
\text { Tocopherol PEG } \\
1000 \text { succinate) }\end{array}$ & $\begin{array}{l}\text { Sonoprecipitation, } \\
\text { ultrasonic } \\
\text { homogenization }\end{array}$ & $\begin{array}{l}\text { To enhance the solubility of } \\
\text { formed nanosuspension }\end{array}$ & $\begin{array}{l}\text { Cur-TPGS NSs showed } \\
\text { higher solubility \& oral } \\
\text { adsorption }\end{array}$ & 30 \\
\hline $\begin{array}{l}\text { Nanosuspension } \\
\text { (crystalline) }\end{array}$ & $<150$ & $\begin{array}{l}\text { Anticancer } \\
\text { compound, } \\
\text { SN } 30191\end{array}$ & Wet milling & $\begin{array}{c}\text { Evaluation of crystalline } \\
\text { nanosuspension as a cancer } \\
\text { drug }\end{array}$ & $\begin{array}{c}\text { Crystalline nanosuspension } \\
\text { showed high tolerance \& } \\
\text { drug delivery }\end{array}$ & 31 \\
\hline $\begin{array}{l}\text { Nanocrystals to } \\
\text { Amorphous } \\
\text { nanosuspension }\end{array}$ & $150-175$ & Curcumin & $\begin{array}{l}\text { Antisolvent } \\
\text { precipitation } \\
\text { method }\end{array}$ & $\begin{array}{c}\text { Enhance bioavailability of } \\
\text { curcumin by nanosizing and } \\
\text { amorphisation }\end{array}$ & $\begin{array}{l}\text { Nanosized \& amorphous } \\
\text { nanosuspension shows the } \\
\text { maximum stability }\end{array}$ & 32 \\
\hline $\begin{array}{c}\text { Crystalline } \\
\text { nanosuspension }\end{array}$ & $200-350$ & $\begin{array}{l}\text { BCS class II/IV } \\
\text { compounds }\end{array}$ & Spray drying & $\begin{array}{l}\text { Enhance dissolution using } \\
\text { nanocrystalline suspensions }\end{array}$ & $\begin{array}{l}\text { Faster dissolution was } \\
\text { obtained subject to drug-to- } \\
\text { excipient ratio }\end{array}$ & 33 \\
\hline Amorphous \& & NA & Nanosuspensions & Freeze drying & Effect of critical formulation & Freeze drying does not & 34 \\
\hline
\end{tabular}




\begin{tabular}{|c|c|c|c|c|c|c|}
\hline $\begin{array}{c}\text { crystalline } \\
\text { nanosuspension }\end{array}$ & & with steric stabilizers & & $\begin{array}{c}\text { temperature (CFT) and } \\
\text { freeze drying on drug's } \\
\text { stability }\end{array}$ & affect drug's stability & \\
\hline $\begin{array}{l}\text { Amorphous \& } \\
\text { crystalline } \\
\text { nanosuspension }\end{array}$ & 300 & Hydrocortisone (HC) & $\begin{array}{c}\text { Microfluidic } \\
\text { nanoprecipitation } \\
\text { (bottom-up) \& wet } \\
\text { milling (top-down) }\end{array}$ & $\begin{array}{l}\text { Bottom up and top down } \\
\text { methods for ophthalmic drug }\end{array}$ & $\begin{array}{l}\text { Top-down showed high } \\
\text { stability as compared to the } \\
\text { bottom-down }\end{array}$ & 35 \\
\hline $\begin{array}{c}\text { Crystalline } \\
\text { nanosuspension }\end{array}$ & $\begin{array}{l}88,122 \\
362\end{array}$ & $\begin{array}{l}\text { Compounds } \\
\text { (celecoxib, griseo- } \\
\text { fulvin, fenofibrate, } \\
\text { and compound-X) }\end{array}$ & $\begin{array}{l}\text { Ultracentrifugation } \\
\quad \& \text { filtration }\end{array}$ & $\begin{array}{c}\text { Dissolution rate dependence } \\
\text { on the Noyes-Whitney } \\
\text { equation }\end{array}$ & Low dependence & 36 \\
\hline $\begin{array}{l}\text { Amorphous and } \\
\text { crystalline } \\
\text { nanosuspensions }\end{array}$ & 274 & Ziprasidone & $\begin{array}{l}\text { Lyophilisation and } \\
\text { milling }\end{array}$ & $\begin{array}{c}\text { Improving drug absorption in } \\
\text { the fasted state (in-vitro } \\
\text { studies) }\end{array}$ & $\begin{array}{c}\text { Amorphous } \\
\text { nanosuspension showed } \\
\text { high absorption }\end{array}$ & 37 \\
\hline $\begin{array}{c}\text { Crystalline \& } \\
\text { amorphous } \\
\text { nanosuspension }\end{array}$ & $323-734$ & Itraconazole (ITZ) & $\begin{array}{l}\text { HME and wet } \\
\text { milling }\end{array}$ & $\begin{array}{c}\text { Effect of methods on } \\
\text { Itraconazole (ITZ) for both in } \\
\text { vitro \& in vivo }\end{array}$ & $\begin{array}{l}\text { HME method showed } \\
\text { higher dissolution \& } \\
\text { bioavailability }\end{array}$ & 38 \\
\hline $\begin{array}{c}\text { Crystalline \& } \\
\text { amorphous } \\
\text { nanosuspension }\end{array}$ & 300 & $\begin{array}{l}\text { Drug/polymeric } \\
\text { complex }\end{array}$ & Wet-milling & $\begin{array}{l}\text { Increase solubility \& } \\
\text { dissolution rate by nanosizing }\end{array}$ & $\begin{array}{l}\text { Higher solubility \& } \\
\text { dissolution rate upon } \\
\text { nanosizing }\end{array}$ & 39 \\
\hline $\begin{array}{c}\text { Amorphous } \\
\text { nanosuspension }\end{array}$ & $>600$ & $\begin{array}{c}\text { Ezetimibe } \\
\text { nanosuspension }\end{array}$ & Precipitation & $\begin{array}{c}\text { Enhance oral bioavailability } \\
\text { of ezetimibe }\end{array}$ & $\begin{array}{l}\text { Amorphous precipitation } \\
\text { increases oral bioavailability }\end{array}$ & 40 \\
\hline $\begin{array}{c}\text { Crystalline } \\
\text { nanosuspension }\end{array}$ & 699 & Fenofibrate & $\begin{array}{l}\text { Bead-milling } \\
\text { method } \\
\text { Spray drying }\end{array}$ & $\begin{array}{c}\text { Effect of methods on } \\
\text { bioavailability \& dissolution }\end{array}$ & $\begin{array}{l}\text { The dissolution was found } \\
\text { faster in the spray dried } \\
\text { powder }\end{array}$ & 41 \\
\hline $\begin{array}{c}\text { Crystalline } \\
\text { nanosuspension }\end{array}$ & 397 & Indomethacin & Spray drying & $\begin{array}{l}\text { Effect of spray drying on } \\
\text { powder yields }\end{array}$ & $\begin{array}{l}\text { High yields with lower } \\
\text { moisture content }\end{array}$ & 42 \\
\hline
\end{tabular}




\section{Size measurement of nanoparticles in suspension}

The size and number of atoms within a single nanoparticle controls the morphological aspects of these particles, in addition to other chemical and physical properties. For instance, the smallest hydrogen atom has a diameter of about 0.074 $\mathrm{nm}$ whereas a lead atom is about $0.32 \mathrm{~nm}$. Therefore in a single nanoparticle, there can be ten to hundreds of atoms present based on the bonding types and composition ${ }^{[16]}$. One of the most important properties attained on transforming micro-sized particles into nanoparticles is the massive increase in the surface area. This increased surface area imparts enhanced solubility and reaction rates for the particles, which is a key desire in modern science. Other properties such as dielectric constant, melting point and even crystal lattice are affected due to the "size effect".

The size measurement for nanoparticles can be done using a range of characterisation techniques such as imaging using electron microscope from SEM and TEM, peak widths at half maximum from X-ray diffraction, surface area analysis from BET and Brownian motion calculation using Dynamic Light Scattering in Zetasizer instrument. The imaging techniques are considered to be relatively easy and quick as compared to others since it can provide visual inspection of the particles as well. However, the sample preparation is a critical step that determines the quality of image an accuracy of size measurements.

The X-ray method is on the other hand considered complex but relatively precise in estimating the average particle size from peak properties. But on a nanoscale, it is also subjected to limitations of sample preparation and orientation to the electron beam. Surface area analysis from BET is relatively simpler to estimate particle size but the assumption of spherical shape for calculation is not applicable to all types of nanoparticles. Furthermore, the inner structure and surface state of particles can affect the calculations and thereby the size of nanoparticles. The application of Zetasizer is widely recognised in literatures for determining the size of particles in nanosuspensions ${ }^{[16,43-45]}$.

A summary of the most common analytical techniques for characterisation of nanoparticles is shown in the Figure 6. These techniques are helpful in studying various aspects of the nanoparticles such as X-ray diffraction for amorphous or 
crystallinity study, SEM/EDX and AFM for surface morphology study, TEM for internal structure study, AGM, VSM and SQUID for magnetic property study and so on.

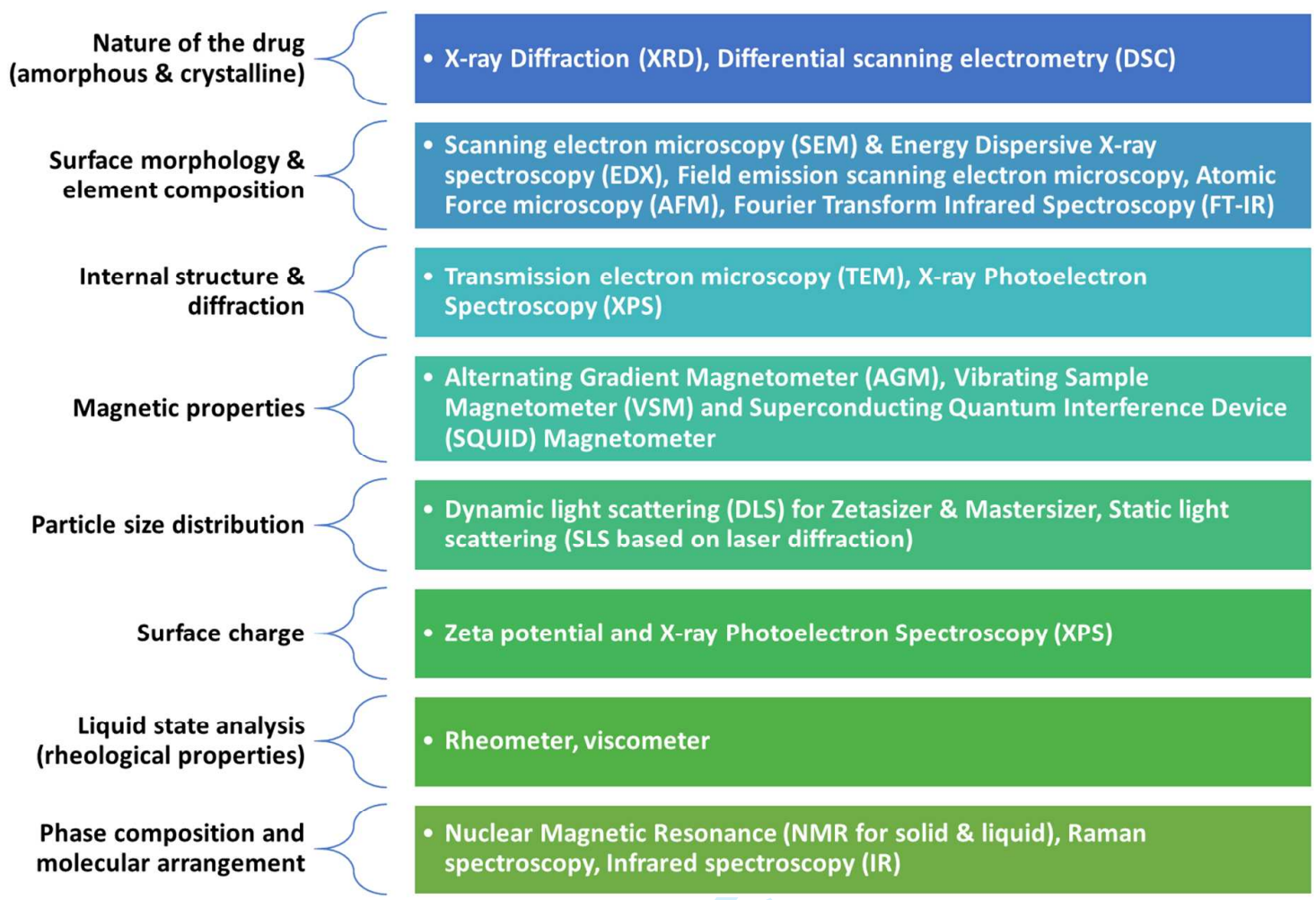

Figure 6: Useful analytical techniques to study various properties of nanoparticles

\section{Amorphous vs Crystalline Nanoparticles in Nanomedicine}

It is possible to synthesise various drug nanoparticles used in nanomedicine as either amorphous or crystalline forms. On one hand, there is a well-defined crystal structure with some crystal defects located on the surface and bulk of the crystalline nanoparticles. On the other hand, structural disorderedness is evident throughout the nanoparticles in amorphous state providing a more porous framework with high structural defects ${ }^{[46-48]}$. These structural differences arise due to different methods of nanoparticles preparation. Both bottom up and top down approaches can produce particles with varying crystallinity and other physio-chemical properties.

Most of the drug nanoparticles are prepared using top down approaches, among which high pressure homogenisation $(\mathrm{HPH})$ is widely used. HPH process consists of 3 main steps ${ }^{[49-54]}$ : 
- Dispersion of powdered drug in a solution of water and stabiliser

- Comminution of coarse particles of drug under low pressure homogenisation to prevent blockage of homogenisation chamber

- High pressure homogenisation using repetitive cycles to attain the desired particle size and distribution

The number of cycles and pressure of homogenisation are the critical factors which control the particle size and distribution. For example, the polydispersity index and particle size of amoitone B nanocrystals is reported to gradually reduce with an increase in number of cycles and homogenisation pressure in a stepwise manner ${ }^{[52]}$. However, once the particles become highly uniform non-aggregated then a continuous increase in the pressure or number of cycles has little effect on particle size and polydispersity index ${ }^{[52]}$.

$\mathrm{HPH}$ is also often combined with precipitation process to prepare nanocrystals. In this process, first the precipitation of drug is done in a liquid medium that produces comminuted drug crystals. Then high pressure homogenisation using repetitive cycles is applied to achieve the desired particle size ${ }^{[55,56]}$. The main requirement of this process is that the drug should dissolve in at least one solvent and get precipitated using a miscible non-solvent. This poses challenges of potential toxicity from solvent media and its complete removal from the final drug preparation ${ }^{[57]}$.

Wet ball milling technique uses a milling chamber to comminute a drug material that is dispersed in water and agitated along with surfactants or stabilisers. In this technique, mechanical shear and attrition is used due to collision of the drug particles with each other, milling media and walls of the milling chamber ${ }^{[58]}$. Small pearls, stainless steel, cross linked polystyrene, glass or ceramic beads of size 0.3 $\mathrm{mm}$ or higher are used as milling media. However, the final size of the drug nanoparticles depends on other factors such as viscosity of the dispersion media, concentration of the surfactant, temperature conditions, duration of milling process and properties of drug dispersed ${ }^{[59]}$.

The bottom up process offer smaller particle sizes than most top down approaches but its production scale is also much smaller. The fundamental of this process is precipitation of drug nanocrystals in two steps procedure: nucleation followed by crystal growth ${ }^{[60]}$. Hence it is important to control the nucleation step since if the 
number of nuclei formed is higher, it will limit the growth of every nuclei. The use of ultrasound in combination to precipitation process results in cavitation effects which can speed up the nucleation process and minimize agglomeration ${ }^{[60,61]}$.

Another bottom up process is called as evaporative precipitation in aqueous solution, where the drugs are dissolved in ethanol at $60^{\circ} \mathrm{C}$. The solution is then added dropwise with constant stirring into water at $0^{\circ} \mathrm{C}$. This temperature difference promotes supersaturation and nucleation which leads to a smaller size as compared to $\mathrm{HPH}$ technique. For example, the anticancer drug riccardin D was prepared as nanocrystals using evaporative precipitation and $\mathrm{HPH}$ technique with a size of 184 $\mathrm{nm}$ and $815 \mathrm{~nm}$ respectively ${ }^{[51]}$. This study shows that a smaller particle size can be prepared using evaporative precipitation as a bottom up process which provides a higher control on particle size.

Precipitation techniques of bottom up processes usually produces nanodrugs of lower crystallinity as various factors affect the polymorphic form of the drug nanoparticles, such as degree of supersaturation, type of solvent-antisolvent, etc. Solid state characterisation techniques such as XRD, NMR, DSC and FTIR can be used to study the crystallinity and other properties. However, the amorphous state of the nanoparticles is thermodynamically favourable during precipitation since it exhibits a metastable state with high energy that imparts quicker solubility of the drug. But, the property of the drug is also a significant factor to determine the resulting state of nanoparticles, as some drugs like lbuprofen mostly precipitates in crystalline state, whereas Cefuroxime axetil precipitates as amorphous particles ${ }^{[62,}$ 63].

The structural differences between the two (crystalline and amorphous) states of nanoparticles impart unique properties to the drugs which is exhibited either as advantages or disadvantages in terms of properties and specific applications. For instance, Table 2 critically studies both amorphous and crystalline drug nanoparticle along with their respective potential merits and demerits ${ }^{[46-48,64-69]}$. 
Table 2. Comparison of amorphous and crystalline nanoparticles

\begin{tabular}{|c|c|c|}
\hline $\begin{array}{l}\text { Types of Drug } \\
\text { Nanoparticles }\end{array}$ & Advantages & Disadvantages \\
\hline \multirow{6}{*}{$\begin{array}{l}\text { Amorphous } \\
\text { NPs }\end{array}$} & $\begin{array}{l}\text { Disorderedness improves } \\
\text { thermodynamic driving force }\end{array}$ & Wide size range ( $\mathrm{nm}$ to $\mu \mathrm{m}$ ) \\
\hline & High water solubility & Abrupt surface areas \\
\hline & Enhanced Dissolution rate & Low impurity of drug \\
\hline & High oral absorption & $\begin{array}{l}\text { Physical and chemical instability in GI } \\
\text { tract }\end{array}$ \\
\hline & $\begin{array}{l}\text { High saturation solubility (Ex- } \\
\text { Chloramphenicol palmitate) }\end{array}$ & High pharmacokinetic variability \\
\hline & Ease of production & Low suitability for intravenous routes \\
\hline \multirow{5}{*}{$\begin{array}{l}\text { Crystalline } \\
\text { NPs }\end{array}$} & $\begin{array}{l}\text { Low pharmacokinetic variability in } \\
\text { patients }\end{array}$ & $\begin{array}{l}\text { Lattice energy barrier for dissolution } \\
\text { limits }\end{array}$ \\
\hline & Narrow size range of crystals $(<1 \mu \mathrm{m})$ & Need stabilisation by surfactants \\
\hline & $\begin{array}{c}\text { Physical and Chemical Stability from } \\
\text { enzymatic degradation }\end{array}$ & $\begin{array}{l}\text { Aggregation due to high surface area } \\
\text { and surface energy }\end{array}$ \\
\hline & High Purity and drug loading (100\%) & Requires extensive crystallisation steps \\
\hline & Suitable for intravenous administration & Low oral absorption \\
\hline
\end{tabular}

\section{Nanosuspensions for drug delivery}

Nanosuspensions are powerful for drug delivery applications and several latest review articles have provided an in depth discussion on the various routes of administration. In brief, it is important to focus on key developments in this area by reviewing strategic articles and routes of administration. For instance, oral drug delivery is one of the most preferred routes of drug administration but is limited due to low oral absorption and bioavailability. Drug nanoparticles in suspension can tackle this problem by increasing the area of absorption under the curve as shown by naproxen nanoparticles with a $218 \%$ increase. Danazol - an inhibitor of gonadotropin when used in suspension showed an increased bioavailability of 82.3 as opposed to conventional dispersion of $5.2 \%{ }^{[6]}$. In addition, lyophilised 
nanosuspensions offer faster dissolution rate with an increased permeability, as shown in case of oleanolic acid ${ }^{[70]}$. A schematic diagram shown in Figure 7 highlights the enhanced permeability and retention (EPR) effect of drug nanocrystals, effective for tumour targeted drug delivery ${ }^{[71]}$.

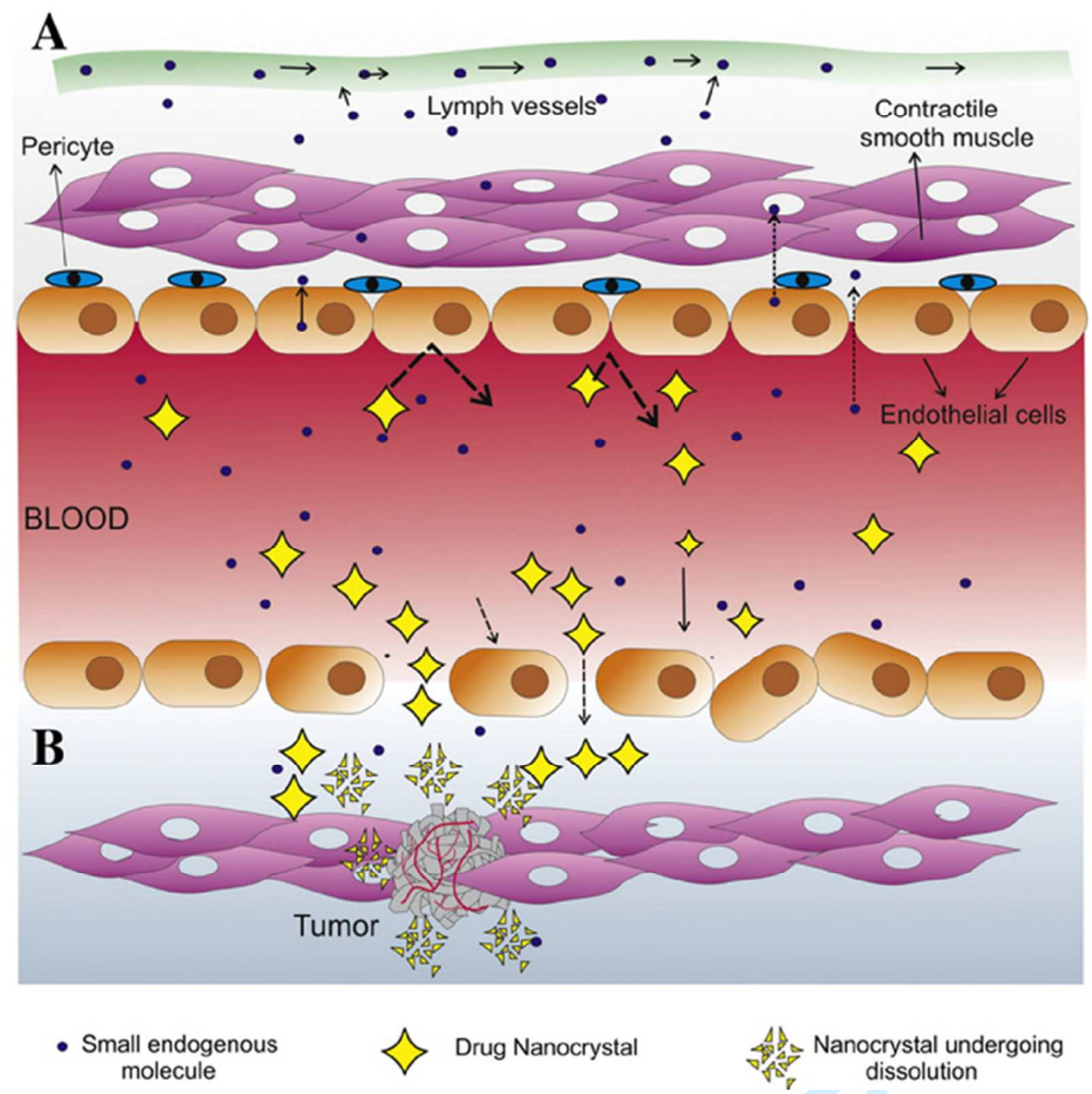

Figure 7: EPR effect; (A) Normal vessel: the narrow gap junctions present in between endothelial cells allow only small molecules to penetrate, screening out colloidal sized particles. Notice the ordered structure of cells in the presence of functional lymphatic drainage. Lymph flow regularly filters out accumulated material. (B) Tumour microenvironment: The vascular endothelium in and around tumour is disjointed, irregular and leaky allowing effective penetration of nanocrystals. Absent or dysfunctional lymphatic vessels further delay clearance of these particles leading to their enhanced accumulation at tumour site (Reproduced with permission from ref [71]). 
Nanosuspensions are also compatible for parenteral routes of drug administration like intravenous, interperitoneal and intra-articular. One of the key requirements for drug molecules administered through parenteral route is to highly soluble or have a particle size of less than $5 \mu \mathrm{m}$ to prevent blockage of capillaries. It has been reported that nanosuspensions have increased the efficiency of parenterally administered drugs like paclitaxel ${ }^{[72]}$, aphidicolin ${ }^{[73]}$, clofazimine ${ }^{[74]}$ and busulfan ${ }^{[75]}$.

Pulmonary drug delivery is dependent on the solubility of the drugs in pulmonary secretions. It is possible to nebulise the aqueous nanosuspensions using ultrasonic or mechanical nebulisers for delivery to lungs. This can lead to a uniform distribution of the drug nanoparticle in the aerosol droplet allowing for rapid dissolution and diffusion in the lungs. Furthermore, the adhesiveness of the drug to the mucosal membrane will be increased and therefore prolonging the drug's residence time at the site of absorption. One such example is seen from budesonide drug that was nebulised successfully using an ultrasonic nebuliser ${ }^{[6]}$.

Other key applications include use of nanosuspensions for ocular drug delivery as shown by dexamethasone study for anti-inflammation activity in rabbit ${ }^{[76]}$, targeted drug delivery as shown by aphidicolin study against Leishmania-infected macrophages [73], mucoadhesion of drug for reducing infection as shown by mucoadhesive Buparvaquone ${ }^{[6]}$ and topical drug delivery ${ }^{[8]}$.

\section{In vitro stability of drug nanocrystals}

Some of the areas of concern for in vitro stability are related to the pharmaceutical application of drug nanocrystals such as agglomeration, crystal growth and sedimentation. Drug nanocrystals can undergo amorphisation, especially upon application of nanosuspension methodologies such as top down and bottom up approaches ${ }^{[77]}$. Stabilisers are normally used to prevent the agglomeration of drug nanocrystals but it was found that drug-polymer interactions can substantially reduce the crystallinity. For instance, a study provided concrete evidence of Naproxen drug undergoing amorphisation due to the generation of amorphous layer on nanocrystals surface when subjected to media milling in the presence of hydroxypropyl methylcellulose ${ }^{[78]}$.

Cell culture assays are generally the standardised protocol for evaluating the performance of drug nanocrystals. However some of the key limitations of these 
assays are linked to their working conditions and parameters. For instance, a fundamental limitation of these assays is due to its finite volume and closed system features. This can greatly affect the therapeutic efficacy and dissolution rate of the drug depending on the administered dose, especially if it is above the drug's saturation solubility. This in turn affects the cytotoxicity based on the incubation time, since the low dissolution rate drugs naturally exhibit lower cytotoxicity effects ${ }^{[79]}$. A recent study has established these results by showing that longer incubation times such as 72 hours, for $240 \mathrm{~nm}$ Camptothecin's drug nanocrystals showed similar cytotoxicity results as that to the solution ${ }^{[80]}$.

Furthermore, a recent study also established the fact that drug nanocrystals can aggregate within the cells to form rough edges with time. This can greatly affect the overall size and shape of the drug nanocrystals and therefore degrade the drug's pharmacokinetics and its release. For instance, in the study, antiretroviral drug Ritonavir was loaded as large drug nanocrystals of about 300 to $900 \mathrm{~nm}$ into the macrophages. It was found that 24 hour post uptake, $68 \%$ of the drug nanocrystals were intact due to aggregation and acted as rough edged reservoirs to sustainably release the drug over a period of 2 weeks and longer ${ }^{[81]}$. As an extension to this work, it was also found that surfactant coating, shape and type of drug nanocrystals were influential parameters which affected its release, uptake and antiretroviral activity. It was found in the study that drug nanocrystals with irregular and round edges showed low cell uptake, while rod shaped drug nanocrystals showing regular and smooth edges showed a rapid uptake and release from macrophages ${ }^{[82]}$.

\section{In vivo stability of drug nanocrystals}

A wide range of factors affect the stability and performance of drug nanocrystals in in vivo, such as the dissolution rate, half-life, charge, shape, particle distribution profile and toxicity effects. Both biological and physicochemical parameters affect the biodistribution and pharmacokinetics of the drug nanocrystals in in vivo. For instance, a study highlighted the effect of agglomeration on the cell's uptake efficiency, showing that drug nanocrystals of size 50-100 nm were not internalised by the cells ${ }^{[83]}$. Furthermore, the un-dissolved drug nanocrystals injected intravenously remained in blood and interacted with plasma proteins that lead to surface opsonisation and formation of protein-drug agglomerates. This facilitates the recognition and clearance of the protein-drug agglomerates from the blood by the 
tissue macrophages and circulating phagocytes that are directly in contact with blood [84].

Dissolution of the drug nanocrystals and its accumulation in liver and spleen are the key limitations which is inherent of the nanocrystals ${ }^{[85]}$. There are several studies which demonstrates the dissolution profile of low cytotoxic drug nanocrystals in in vivo models such as rats, dogs, rabbits, etc and also pinpoint their accumulation in tissues, especially the macrophages of spleen and Kupffer cells of the liver ${ }^{[86]}$. Figure 8 presents a recent study showed the in vivo application of $450 \mathrm{~nm}$ Veirapine nanocrystals in mice ${ }^{[87]}$. The study indicated an EPR effect in the liver of mice for the drug nanocrystals as compared to drug in solution. However, the size of drug nanocrystals significantly affects their dissolution and accumulation profiles. For instance, a study showed the use of nanocrystals of Oridonin drug with two sizes ranges; $100 \mathrm{~nm}$ and $900 \mathrm{~nm}$. It was found that when these drug nanocrystals were IV injected in rabbits, the $100 \mathrm{~nm}$ nanocrystals showed complete dissolution within 10 minutes whereas the $900 \mathrm{~nm}$ nanocrystals underwent complete dissolution in 2 hours ${ }^{[88]}$.

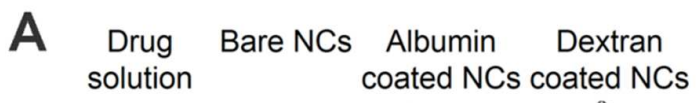




\section{Benefits of nanosuspensions in drug delivery}

There are several benefits of nanosuspensions for use in drug delivery applications, such as ${ }^{[89-91]}$ :

- improves solubility of drugs insoluble in organic media and water, as alternative to lipid systems

- helps to decrease the dosage requirements by increasing absorption and bioavailability of drugs

- helps in formulations of high melting point and high log $P$ value drugs

- reduces systemic toxicity of drugs

- increased physical stability of drugs

- offers high resistance to oxidation and hydrolysis

- offers passive targeting

\section{Conclusion}

To this date, various types of nanoparticles are employed in the field of nanomedicine, for drug delivery, imaging, diagnostics and several other applications. Even though a large number of studies are dedicated towards the carrier molecules such as organic and inorganic nanoparticles, it is important to understand the physiochemical properties of the effective drug itself for both in vivo and in vitro studies. There are several different processes that are used for synthesising the drug nanoparticles in both crystalline and amorphous forms, but these processes are broadly classified as top down and bottom up approaches. It is therefore important to choose the right methods of nanosizing the drug to control the degree of crystallinity and properties like particle size, morphology and surface areas.

Nanosuspensions are an attractive solution for drug delivery, especially for oral and dermal routes of administration and are in turn favourable towards both amorphous and crystalline drug nanoparticles. It is highly anticipated that nanosuspension can dramatically improve the drug efficacy and bioavailability for all major drug classes, provided suitable solvents and stabilising agents are discovered. Therefore further studies should be directed towards finding a surfactant free route of drug delivery such as the food-derived or blood-derived proteins which poses no toxicity problems in vivo. 


\section{Future Perspective}

Targeted nanodrugs have already showed higher performance as compared to conventional drugs through almost all routes of administration. However the number of nanomedicines commercialising every year is far less than the total articles published. There seems to be a gap that is created between the laboratory tests and actual clinical trials due to the various differences that arise during scale up process and clinical trial stage. Therefore, adequate characterisation should be carried out for the synthesised drug nanoparticles and performance should be evaluated based on specific parameters such as surface area, surface charge and dispensability in nanosuspension. Foremost, crystallisation methods should be standardised for certain drug classes and appropriate control should be established on the aspect ratio of the drug nanocrystals for potential drug delivery both via passive and active targeting routes.

\section{Acknowledgements}

Authors thank to UK India Education and Research Initiative (UKIERI) as this work has partly been supported by on-going project with the contract number DST/INT/UK/P-82/2014 as a part of project dissemination activity.

\section{Financial \& Competing interests disclosures}

The authors have no relevant affiliations or financial involvement with any organisation or entity with a financial interest in or financial conflict with the subject matter or materials discussed in the manuscript apart from those disclosed. 


\section{Executive summary}

\section{Fabrication of drug nanoparticles in suspension}

- Drug particles in nanosuspension mitigate solubility and bioavailability issues of drugs.

- Two main approaches for the synthesis of nanosuspension such as top-down and bottom up.

- Crystalline and amorphous nanoparticle with variety of shapes, sizes and morphology can be designed

- A range of characterisation techniques can be used for tuning the properties of drug nanoparticles

\section{Nanosuspensions in Drug Delivery}

- Poor solubility of drug molecules triggered the development of drug nanoparticulates for drug delivery

- Nanosuspensions are highly desirable for oral route of drug administration

- It is also compatible for parenteral routes of drug administration like intravenous, interperitoneal and intra-articular.

- Nebulising of nanosuspensions aids the drugs to be used for pulmonary routes

- Drug nanocrystals have higher EPR (enhanced permeability and retention) effect

- In vitro studies of drug nanocrystals are limited by agglomeration, crystal growth and sedimentation

- In vivo studies of drug nanocrystals face challenges due to bio-distribution and dissolution barriers along with accumulation tendencies in liver and spleen. 


\section{References}

The author have used the following keys to highlight the articles which are of "interest" and of "considerable interest"

${ }^{*}=$ of interest, ${ }^{* *}=$ of considerable interest

1. Varkony $\mathrm{H}$, Weinstein $\mathrm{V}$, Klinger $\mathrm{E}$, et al:: The glatiramoid class of immunomodulator drugs. Expert Opin. Pharmacother. 10, 657-668 (2009)

2. Robinson DM, Keating GM: Colesevelam: a review of its use in hypercholesterolemia. Am. J. Cardiovasc. Drugs. 7 (6), 453-465 (2007)

3. Mcgowan I, Gomez K, Bruder K, et al.: Phase 1 Randomized Trial of the Vaginal Safety and Acceptability of SPL7013 Gel (VivaGelß) in Sexually Active Young Women (MTN-004). AIDS (London, England). 25(8), 1057-1064 (2011)

4. Raggi P, Vukicevic S, Moyses RM, Wesseling K, Spiegel DM: Ten-year experience with sevelamer and calcium salts as phosphate binders. Clin. J. Am. Soc. Nephrol., 5 (Suppl. 1), S31-40 (2010)

5. Brough C, Williams RO. Amorphous solid dispersions and nano-crystal technologies for poorly water-soluble drug delivery. Int $J$ Pharmaceut 453(1), 157-166 (2013).

6. Prabhakar C, Krishna KB: A review on nanosuspensions in drug delivery. Internl. Journl. Pharm. \& Bio Sci. 2(1), 549-558 (2011)

7. Zhang L, Chen Z, Yang K, Liu C, Gao J, Qian F: $\beta$-Lapachone and Paclitaxel Combination Micelles with Improved Drug Encapsulation and Therapeutic Synergy as Novel Nanotherapeutics for NQO1-Targeted Cancer Therapy. Mol. Pharmaceu. 12, 3999-4010 (2015)

8. Chingunpituk J: Nanosuspension technology for drug delivery. Walailak J. Sci. \& Tech. 4(2), 139-153 (2007)

9. Patravale VB, Date AA, Kulkarni RM: Nanosuspensions: a promising drug delivery strategy. J. Pharm. Pharmaco. 56(7), 827-840 (2004)

10. Junyaprasert VB, Morakul B: Nanocrystals for enhancement of oral bioavailability of poorly water-soluble drugs, Asian J. Pharmaceu. Sci. 10(1), 13-23 (2015)

11. Magdalene R: Pure drug nanoparticles for the formulation of poorly soluble drugs. NewDrugs. 3, 62-68 (2001)

12. Möschwitzer J, Müller R.H: Drug nanocrystals - the universal formulation approach for poorly soluble drugs, D. Thassu, M. Deleers, Y. Pathak (Eds.), Nanoparticulate drug delivery systems, Informa Healthcare. 71-88, New York (2007)

13. Gao L, Zhang D, Chen M: Drug nanocrystals for the formulation of poorly soluble drugs and its application as a potential drug delivery system, $J$ Nanopart Res, 10, 845-862 (2008)

14. Junghanns J.U.A.H, Müller R.H: Nanocrystal technology, drug delivery and clinical appications, Int J Nanomedicine. 3 (3), 295-309 (2008)

15. H. Chen, C. Khemtong, X. Yang, et al., Nanonization strategies for poorly water-soluble drugs, Drug Discov Today, 16 (7/8) (2011), pp. 354-360

16. Hosokawa M, Nogi K, Naito M, Yokoyama T: Nanoparticle Technology Handbook: Nanoparticles and Quantum dots, edited by Klaus D. Sattler, CRC Press (2011) 
17. Wang GD, Mallet FP, Ricard F, Heng JYY. Pharmaceutical nanocrystals. Curr Opin Chem Eng 1(2), 102-107 (2012).

** The role of surface properties on drug's dissolution rate and targeted drug delivery is discussed in detail here. A special section is dedicated to the key technical challenges and environmental impact during drug nanocrystal processing.

18. Tuomela A, Saarinen J, Strachan CJ, Hirvonen J, Peltonen L. Production, applications and in vivo fate of drug nanocrystals. J Drug Deliv Sci Tec 3421 31 (2016).

19. Banavath H, Raju KS, Ansari MT, Ali MS, Pattnaik G: Nanosuspension: an attempt to enhance bioavailability of poorly soluble drugs. Intern. J. Pharmaceu. Sci. Res. 1(9), 1-11 (2010)

20. Reddy GA, Anilchowdary Y: Nanosuspension technology: a review. IJPI's J. Pharmaceu. Cosm., 2 (8), 47-52 (2012)

21. Parrot EL: Comminution. Encycl. of Pharma. Tech. 3, 101-121. Marcel Decker Inc., New York (1990)

22. Hütterauch $R$, Fricke $S$, Zielke $P$ : Mechanical activation of pharmaceutical systems. Pharm. Res. 2, 302-306 (1985)

* The effects of milling on the drug nanocrystals are highlighted here, especially using paracetamol drug and studying its surface properties.

23. Heng JYY, Thielmann F, Williams DR: The effects of milling on the surface properties of form I paracetamol crystals. Pharm. Res. 23, 1918-1927 (2006)

24. Rabinow BE: Nanosuspensions in drug delivery. Nat. Rev. Drug Discov. 3, 785-796 (2004)

25. Date AA, Patravale VB: Current Strategies for engineering drug nanoparticles. Curr. Opin. Colloid Interface Sci. 9, 222-235 (2004)

26. Patel VR, Agrawal YK: Nanosuspension: An approach to enhance solubility of drugs. J. Adv. Pharmaceu. Tech. \& Res., 2(2), 81-87 (2011)

27. Romero GB, Arntjen A, Keck CM, Müller RH: Amorphous cyclosporin A nanoparticles for enhanced dermal bioavailability. Int J Pharm. 498(1-2), 217224 (2016)

28. Tran TT, Tran $\mathrm{PH}$, Nguyen $\mathrm{MN}$, et al.: Amorphous isradipine nanosuspension by the sonoprecipitation method. Int J Pharm. 474(1-2), 146-150 (2014)

29. Hong C, Dang Y, Lin G, et al:: Effects of stabilizing agents on the development of myricetin nanosuspension and its characterization: an in vitro and in vivo evaluation. Int J Pharm. 477(1-2), 251-260 (2014)

30. Shin GH, Li J, Cho JH, Kim JT, Park HJ. Enhancement of Curcumin Solubility by Phase Change from Crystalline to Amorphous in Cur-TPGS Nanosuspension. J Food Sci. 81(2), N494-501 (2016)

31. Sharma P, Zujovic ZD, Bowmaker GA, Marshall AJ, Denny WA, Garg S: Evaluation of a crystalline nanosuspension: polymorphism, process induced transformation and in vivo studies. Int J Pharm 408(1-2), 138-151 (2011)

32. Aditya NP, Yang $\mathrm{H}$, Kim S, Ko S: Fabrication of amorphous curcumin nanosuspensions using beta-lactoglobulin to enhance solubility, stability, and bioavailability. Colloids Surf B Biointerfaces. 127, 114-121 (2015)

33. Kumar S, Xu X, Gokhale R, Burgess DJ: Formulation parameters of crystalline nanosuspensions on spray drying processing: a DoE approach. Int J Pharm. 464(1-2), 34-45 (2014)

34. Beirowski J, Inghelbrecht $\mathrm{S}$, Arien $\mathrm{A}$, Gieseler $\mathrm{H}$ : Freeze drying of nanosuspensions, 2: the role of the critical formulation temperature on stability of drug nanosuspensions and its practical implication on process design. $J$ Pharm Sci. 100(10), 4471-4481 (2011) 
35. Ali HS, York P, Ali AM, Blagden N: Hydrocortisone nanosuspensions for ophthalmic delivery: A comparative study between microfluidic nanoprecipitation and wet milling. J Control Release. 149(2), 175-181 (2011)

36. Murdande SB, Shah DA, Dave RH: Impact of nanosizing on solubility and dissolution rate of poorly soluble pharmaceuticals. J Pharm Sci. 104(6), 2094$2102(2015)$

37. Thombre AG, Shah JC, Sagawa K, Caldwell WB: In vitro and in vivo characterization of amorphous, nanocrystalline, and crystalline ziprasidone formulations. Int J Pharm. 428(1-2), 8-17 (2012)

38. Zhang $\mathrm{K}$, Yu H, Tang X., et al.: Increased dissolution and oral absorption of itraconazole/soluplus exrudate compared with itraconazole nanosuspension. Euro. J. Pharamceu. Biopharma. 85, 1285-1292 (2013)

39. Dai WG, Dong LC, Song YQ: Nanosizing of a drug/carrageenan complex to increase solubility and dissolution rate. Int J Pharm. 342(1-2), 201-207 (2007)

40. Thadkala K, Nanam PK, Rambabu B, Sailu C, Aukunuru J: Preparation and characterization of amorphous ezetimibe nanosuspensions intended for enhancement of oral bioavailability. Int J Pharm Investig. 4(3), 131-137 (2014)

41. Zuo B, Sun Y, Li H et al.: Preparation and in vitro/in vivo evaluation of fenofibrate nanocrystals. Int J Pharm. 455(1-2), 267-275 (2013)

42. Kumar S, Gokhale R, Burgess DJ: Quality by Design approach to spray drying processing of crystalline nanosuspensions. Int J Pharm. 464(1-2), 234-242 (2014)

43. Fissan H, Ristig S, Kaminski H, Asbach C, Epple M: Comparison of different characterization methods for nanoparticle dispersions before and after aerosolization, Anal. Methods, 6, 7324-7334 (2014)

44. Sahu BP, Das MK: Nanosuspension for enhancement of oral bioavailability of felodipine, App. Nanosci., 4(2), 189-197 (2014)

45. Attari Z, Bhandari A, Jagadish PC, Lewis S: Enhanced ex vivo intestinal absorption of olmesartan medoxomil nanosuspension: Preparation by combinative technology, Saudi Pharmaceu. J. 24(1), 57-63 (2016)

46. Mooter G: The use of amorphous solid dispersions: a formulation strategy to overcome poor solubility and dissolution rate. Drug Discov Today Technol. 9, e79-e85 (2012)

47. Zhang $\mathrm{M}$, Li $\mathrm{H}$, Lang $\mathrm{B}$, et al: Formulation and delivery of improved amorphous fenofibrate solid dispersion prepared by thin film freezing. Eur $J$ Pharm Biopharm., 82, 534-544 (2012)

48. Shegokar R, Muller RH: Nanocrystals: industrially feasible multifunctional formulation technology for poorly soluble actives. Int. J. Pharm. 399(1-2), 129-139 (2010)

* Bottom up and top down technologies are critically evaluated using various drug examples. Also, it focusses on smartCrystals and 2 main routes of administration (IV and Oral).

49. Talekar M, Ganta S, Amiji M et al: Development of PIK-75 nanosuspension formulation with enhanced delivery efficiency and cytotoxicity for targeted anticancer therapy. Int. J. Pharm. 450(1-2), 278-289 (2013)

50. Gao L, Zhang D, Chen $\mathrm{M}$ et al: Studies on pharmacokinetics and tissue distribution of oridonin nanosuspensions. Int. J. Pharm. 355(1-2), 321-327 (2008)

51. Liu G, Zhang D, Jiao $Y$ et al.: In vitro and in vivo evaluation of riccardin $D$ nanosuspensions with different particle size. Colloids Surface. B 102, 620626 (2013) 
52. Hao L, Wang $X$, Zhang $D$ et al.: Studies on the preparation, characterization and pharmacokinetics of Amoitone B nanocrystals. Int. J. Pharm. 433(1-2), 157-164 (2012)

53. Zheng $\mathrm{D}$, Wang $\mathrm{Y}$, Zhang $\mathrm{D}$ et al.: in vitro antitumor activity of silybin nanosuspension in PC-3 cells. Cancer Lett. 307(2), 158-164 (2011)

54. Wang $Y$, Ma $Y$, Zheng $Y$ et al:: In vitro and in vivo anticancer activity of a novel puerarin nanosuspension against colon cancer, with high efficacy and low toxicity. Int. J. Pharm. 441(1-2), 728-735 (2013)

55. Lee SE, Bairstow SF, Werling JO et al.: Paclitaxel nanosuspensions for targeted chemotherapy - nanosuspension preparation, characterization, and use. Pharm. Dev. Technol. 19(4), 438-453 (2014)

56. Zhao YX, Hua HY, Chang M, Liu WJ, Zhao Y, Liu HM: Preparation and cytotoxic activity of hydroxycamptothecin nanosuspensions. Int. J. Pharm. 392(1-2), 64-71 (2010)

57. Keck CM, Muller RH: Drug nanocrystals of poorly soluble drugs produced by high pressure homogenisation. Eur. J. Pharm. Biopharm. 62(1), 3-16 (2006)

58. Niwa T, Miura S, Danjo K: Universal wet-milling technique to prepare oral nanosuspension focused on discovery and preclinical animal studies development of particle design method. Int. J. Pharm. 405, 218-227 (2011)

59. Merisko-Liversidge E, Liversidge GG: Nanosizing for oral and parenteral drug delivery: a perspective on formulating poorlywater soluble compounds using wet media milling technology. Adv. Drug Deliv. Rev. 63, 427-440 (2011)

60. Hollis CP, Li T: Nanocrystals production, characterization, and application for cancer therapy. In: Nanoparticulate Drug Delivery Systems: Strategies, Technologies, and Applications. Yeo Y (Ed.). John Wiley \& Sons, Inc., NY, USA, 181-206 (2013)

61. Luque De Castro MD, Priego-Capote F: Ultrasound-assisted crystallization (sonocrystallization). Ultrason. Sonochem. 14(6), 717-724 (2007)

62. Sinha B, Muller RH, Moschwitzer JP: Bottom-up approaches for preparing drug nanocrystals: formulations and factors affecting particle size. Int. J. Pharm. 453, 126-141 (2013)

** Various bottom up methodologies were critically discussed, followed by several process parameters which affect the particle size of drug nanocrystals.

63. Nie FL, Zheng YF, Wei SC, Wang DS, Yu ZT, Salimgareeva GK, Polyakov AV, Valiev RZ: In vitro and in vivo studies on nanocrystalline Ti fabricated by equal channel angular pressing with microcrystalline $\mathrm{CP} \mathrm{Ti}$ as control. $J$ Biomed Mater Res Part A, 101A, 1694-1707 (2013)

64. Merisko-Liversidg E: Nanosizing:"End-to-End" Formulation Strategy for Poorly Water-Soluble Molecules. Discov. Devel. Mol. with Opt. Drug-Like Prop. 437467, Springer New York (2015)

65. Gao L, Liu G, Ma J et al.: Application of drug nanocrystal technologies on oral drug delivery of poorly soluble drugs. Pharm. Res. 30(2), 307-324 (2013)

66. Merisko-Liversidge E, Sarpotdar P, Bruno J et al.: Formulation and antitumor activity evaluation of nanocrystalline suspensions of poorly soluble anticancer drugs. Pharm. Res. 13(2), 272-278 (1996)

67. Xia D, Quan P, Piao $\mathrm{H}$ et al.: Preparation of stable nitrendipine nanosuspensions using the precipitation-ultrasonication method for enhancement of dissolution and oral bioavailability. Eur. J. Pharm. Sci. 40(4), 325-334 (2010) 
68. Chong-Hui G, Grant DJW: Estimating the relative stability of polymorphs and hydrates from heats of solution and solubility data. J Pharmacol Sci. 909, 1277-87 (2001)

69. Hancock BC, Parks M: What is the true solubility advantage for amorphous pharmaceuticals? Pharmacol Res. 174, 397-404 (2000)

70. Vaghela A, Jain M, Limbachiya H, Bharadia DP: Nanosuspension technology. Intern. J. Univ. Pharm. and Life Sci. 2(2), 306-317 (2012)

71. Pawar VK, Singh Y, Meher JG, Gupta S, Chourasia MK. Engineered nanocrystal technology: in-vivo fate, targeting and applications in drug delivery. J Control Release 183 51-66 (2014).

* In vivo fate and various routes of administration are discussed using various drug nanocrystal studies that focus on engineering the drug nanoparticles.

72. Merisko-Liversidge E, Liversidge GG, Cooper ER: Nanosizing: a formulation approach for poorly-water-soluble compounds. Euro. J. Pharmaceu. Sci., 18, (2), 113-120 (2003)

73. Kayser O, Nanosuspensions for the formulation of aphidicolin to improve drug targeting effects against Leishmania infected macrophages. Intern. J. Pharmaceu. 196(2), 253-256 (2000)

74. Peters K, Leitzke S, Diederichs JE, et al.: Preparation of a clofazimine nanosuspension for intravenous use and evaluation of its therapeutic efficacy in murine Mycobacterium avium infection. J. Antimicro. Chemo., 45(1), 77-83 (2000)

75. Rabinow BE: Nanosuspensions for parenteral delivery. Nanoparticulate Drug Delivery Systems, 33-49, Informa Healthcare, London, UK (2007)

76. McMillan J, Batrakova E, Gendelman HE: Cell delivery of therapeutic nanoparticle. Prog. in Molec. Bio. and Translat. Sci. 104, 571-572, Elsevier, New York, NY, USA (2011)

77. Willart JF, Descamps M. Solid State Amorphization of Pharmaceuticals. Mol Pharmaceut 5(6), 905-920 (2008).

78. Kayaert P, Anne M, Van Den Mooter G. Bead layering as a process to stabilize nanosuspensions: influence of drug hydrophobicity on nanocrystal reagglomeration following in-vitro release from sugar beads. J Pharm Pharmacol 63(11), 1446-1453 (2011).

79. Liu F, Park JY, Zhang Y et al. Targeted Cancer Therapy With Novel High Drug-Loading Nanocrystals. J Pharm Sci-Us 99(8), 3542-3551 (2010).

80. Zhang H, Hollis CP, Zhang Q, Li TL. Preparation and antitumor study of camptothecin nanocrystals. Int J Pharmaceut 415(1-2), 293-300 (2011).

** Effect of crystallisation on the bioavailability and solubility of antitumor drug Camptothecin is demonstrated, as compared to drug salt solution.

81. Nowacek AS, Mcmillan J, Miller R, Anderson A, Rabinow B, Gendelman HE. Nanoformulated Antiretroviral Drug Combinations Extend Drug Release and Antiretroviral Responses in HIV-1-Infected Macrophages: Implications for NeuroAIDS Therapeutics. J Neuroimmune Pharm 5(4), 592-601 (2010).

82. Nowacek AS, Balkundi S, Mcmillan J et al. Analyses of nanoformulated antiretroviral drug charge, size, shape and content for uptake, drug release and antiviral activities in human monocyte-derived macrophages. J Control Release 150(2), 204-211 (2011).

83. Muller RH, Gohla S, Keck CM. State of the art of nanocrystals - Special features, production, nanotoxicology aspects and intracellular delivery. Eur $J$ Pharm Biopharm 78(1), 1-9 (2011). 
84. Karmali PP, Simberg D. Interactions of nanoparticles with plasma proteins: implication on clearance and toxicity of drug delivery systems. Expert Opin Drug Del 8(3), 343-357 (2011).

85. Tian XN, Li $\mathrm{H}$, Zhang $\mathrm{DR}$ et al. Parenteral nanosuspension of a novel synthesized antitumor candidate: Investigation of tissue biodistributions and plasma pharmacokinetics. Colloid Surface A 436 868-872 (2013).

* Plasma pharmacokinetics and tissue biodistribution studies were done using in vivo mice model and a parenteral nanosuspension for antitumor targeted drug delivery.

86. Tian XN, Li H, Zhang DR et al. Nanosuspension for parenteral delivery of a pterphenyl derivative: Preparation, characteristics and pharmacolcinetic studies. Colloid Surface B 108 29-33 (2013).

87. Shegokar R, Singh KK. Surface modified nevirapine nanosuspensions for viral reservoir targeting: In vitro and in vivo evaluation. Int J Pharmaceut 421(2), 341-352 (2011).

* Antiviral drug Nevirapine was used as a model drug to formulate surface modified nanosuspension and study the EPR effect and biodistribution, when administered IV into rat model

88. Gao L, Zhang DR, Chen MH et al. Studies on pharmacokinetics and tissue distribution of oridonin nanosuspensions. Int J Pharmaceut 355(1-2), 321-327 (2008).

89. Verma S, Lan Y, Gokhale R, Burgess DJ: Quality by design approach to understand the process of nanosuspension preparation, Intern. J. Pharmaceu. 377 (1-2), 185-198 (2009)

90. Liu P, Rong X, Laru J, et al:: Nanosuspensions of poorly soluble drugs: preparation and development by wet milling. Intern. J. Pharmaceu. 411(1-2), 215-222 (2011)

91. Ibrahim HM, Ismail HR,. Lila AEA, et al.: Formulation and optimization of ocular poly-D, L-lactic acid nano drug delivery system of amphotericin-B using box behnken design. Intern. J. Pharm. Pharmaceu. Sci., 4(2), 342-349 (2012) 